Maurer School of Law: Indiana University

Digital Repository @ Maurer Law

1989

\title{
Criminal Justice Decision Making as a Stratification Process: The Role of Race and Stratification Resources in Pretrial Release
}

\author{
Ilene H. Nagel \\ Indiana University School of Law \\ Celesta A. Albonetti \\ Temple University \\ Robert M. Hauser \\ University of Wisconsin - Madison \\ John Hagan \\ University of Toronto
}

Follow this and additional works at: https://www.repository.law.indiana.edu/facpub

Part of the Criminal Law Commons, and the Criminology and Criminal Justice Commons

\section{Recommended Citation}

Nagel, Ilene H.; Albonetti, Celesta A.; Hauser, Robert M.; and Hagan, John, "Criminal Justice Decision Making as a Stratification Process: The Role of Race and Stratification Resources in Pretrial Release" (1989). Articles by Maurer Faculty. 2083.

https://www.repository.law.indiana.edu/facpub/2083

This Article is brought to you for free and open access by the Faculty Scholarship at Digital Repository @ Maurer Law. It has been accepted for inclusion in Articles by Maurer Faculty by an authorized administrator of Digital Repository @ Maurer Law. For more information, please contactrvaughan@indiana.edu. 


\title{
Criminal Justice Decision Making as a Stratification Process: The Role of Race and Stratification Resources in Pretrial Release
}

\author{
Celesta A. Albonetti, ${ }^{1}$ Robert M. Hauser, ${ }^{2}$ John Hagan, ${ }^{3}$ and \\ Ilene H. Nagel ${ }^{4}$
}

\begin{abstract}
Our purpose is to bridge the criminal justice and stratification research literatures and to pursue the argument that homologous structural principles stratify allocation processes across central institutions of American society. The principle observed here in the making of bail decisions, as in earlier studies of the allocation of earnings, is that stratification resources operate to the greater advantage of whites than blacks. The operation of this principle is established through the estimation of covariance structure models of pretrial release decisions affecting 5660 defendants in 10 federal courts. Education and income are treated in this study as observed components of a composite construct, stratification resources, which works to the greater advantage of whites. Prior record is also found to operate to the greater advantage of whites. Two further variables, dangerousness and community ties, increase bail severity among blacks and whites. While the effect of community ties has been legally legitimized since the Bail Reform Act of 1966, the effect of dangerousness was not so legitimized until the Bail Reform Act of 1984. However, because our data precede the latter act, they confirm that this act simply reinstitutionalized earlier practice. Meanwhile, our race-specific findings may explain why although this and earlier studies find negligible main effects of race on criminal justice outcomes, black Americans nonetheless perceive more criminal injustice than do whites. In the criminal justice system, as in other spheres of American society, whites receive a better return on their resources, but our findings that the statutory severity of the offense and dangerousness work to the relative disadvantage of white defendants challenges conflict and labeling theory's one-dimensional characterization of black defendant disadvantage.
\end{abstract}

KEY WORDS: stratification resources; race-specific effects; discretion; pretrial release decision; covariance model.

\footnotetext{
${ }^{1}$ Department of Criminal Justice, Gladfelter Hall, Temple University Philadelphia, Pennsylvania 19122.

${ }^{2}$ Department of Sociology and Center of Demography and Ecology, University of WisconsinMadison, Madison, Wisconsin 53706.

${ }^{3}$ Canadian Institute of Advanced Research-Statistics Canada, University of Toronto, Toronto, Ontario, Canada.

${ }^{4}$ Law School, Indiana University, Bloomington, Indiana 47401.
} 


\section{INTRODUCTION}

Are there structural principles that stratify allocation processes across the central institutions of American society? Status attainment and class analysis traditions of sociological research both suggest affirmative answers to this question. With regard to the criminal justice system, both traditions make their cases for such an assumption in intriguing ways. The status attainment tradition notes a remarkable regularity in the way respondents rank the seriousness of crimes and punishments, a regularity that parallels rankings of occupational prestige (Rossi et al., 1974; Blumstein et al., 1983). The class analysis tradition notes that it was not until the nineteenth century and the successful establishment of capitalist modes of production that fixed periods of imprisonment proportional to the ranked seriousness of crimes became a guiding principle of criminal punishment (Humphries and Greenberg, 1984). Of course, both traditions can also note the parallel emphasis placed on equality of treatment in the criminal justice system (e.g., Balbus, 1977) and on equality of opportunity in the wider economy (e.g., Featherman and Hauser, 1978). But it is the attention given to the patterning of inequalities relative to such expectations that makes both these traditions of sociological research of particular interest in the study of criminal justice decision making, as a stratification system guided by structural principles like those of other institutions of allocation. ${ }^{5}$

The logic of the above arguments is not in question, nor is the importance of establishing a correspondence between criminal justice decision making and other stratification systems. However, doing so requires greater evidence of similar structuring principles, particularly with regard to patterned inequalities, than currently exists in the criminal justice research literature. The problem may be that studies of criminal justice decision making have focused with rather inconsistent results, for example, on issues of racial inequality, while they have neglected the connection of race to other aspects of the stratification process (but see Lizotte, 1978; Hagan and Bumiller, 1983).

A convincing demonstration that homologous structural principles underlie criminal justice decision making and other allocation processes requires a combined consideration of race and other stratification resources (Farnworth and Horan, 1980). One of the most intriguing findings in the

\footnotetext{
${ }^{5}$ For purposes of illustration, the education system is seen as an institution allocating credentials that serve to legitimate practice within fields of expertise. Similarly, the criminal justice system can be seen as an institution allocating justice as prescribed by substantive and procedural law within broad discretionary limits. At the pretrial release decision, magistrates dispense levels of liberty with the most severe measure of punitiveness, that of the denial of liberty during pretrial processing.
} 
stratification literature is that black males receive lower returns in income for their educational achievements than do whites (Weiss, 1970; Siegel, 1965; Duncan, 1969; Wright, 1978). Although there is some evidence of change in these patterns over time (Hout, 1984; Featherman and Hauser, 1978; Wilson, 1978), the unequal returns that blacks and whites historically have received on their resources remains as evidence of an important structural principle at work in the stratification of American society. Below we look for evidence of the operation of such a principle at an early stage of the criminal justice process, the making of pretrial release decisions. First, however, we must explore the nature of these decisions and our approach to the analysis of this stratification process.

\section{PRETRIAL RELEASE DECISIONS}

Pretrial release decisions are the culmination of a low-visibility allocation process. Although these decisions receive little public attention, especially at the federal level, it is increasingly apparent that these early determinations exert a substantial effect on subsequent decisions of greater visibility. For example, Goldkamp (1979; see also Hagan et al., 1980; Lizotte, 1978) found that defendants detained in jail during pretrial stages of felony prosecution received more severe sentences. It is argued that being detained in jail decreases a defendant's ability to build a defense and that the stigma of detainment itself further disdvantages defendants, especially in jury trials. Research has sought, therefore, to determine what types of defendants are most likely to be detained prior to trial, focusing particularly on the role of legal and extralegal attributes in the making of these decisions. Below we operationalize two extralegal attributes, education and income, as indicators of a construct we will call stratification resources. ${ }^{6}$ Following the lead of earlier stratification research, our interest is in examining the possible interaction of race with these stratification resources and other legal and extralegal variables in structuring the allocation of pretrial release. Our guiding hypothesis reflects the broader structural principle noted above: that stratification resources operate to the greater advantage of whites than blacks. Before we explore this hypothesis further, however, we must introduce a debate about bail that underwrites the current legislative definition of criteria that are legally relevant to pretrial release decisions.

Critics of America's early and largely cash bail system have argued that the only legal function of bail was to assure the return of the accused

\footnotetext{
${ }^{6}$ We call this construct variable stratification resources in a conscious effort to bridge the status attainment and class analysis traditions. We could have called this variable status or class resources. The point is that stratification resources can be regarded as either status or class resources or both.
} 
for subsequent hearings (Beeley, 1927; Morse and Beattie, 1932; Foote, $1954,1959)$. Proponents of this position, then and now, insist that preventive detention prior to trial violates the constitutional rights of the accused and is contrary to the principles of the presumption of innocence. Opponents of this position (Mitchell, 1969; Hess, 1971) maintain that the legitimate function of bail is twofold: to assure the appearance of the accused and to protect the community from dangerous defendants.

An analysis of Supreme Court decisions of the 1950s and early 1960s reveals that other than a broadly conceived "right to bail" in noncapital cases prior to trial, no real judicial consensus on pretrial release was established. ${ }^{7}$ The form of bail and the criteria to be considered in its determination remained uncertain. Congress entered the debate with the passage of the Bail Reform Act of $1966 .{ }^{8}$ This act attempted to reform the excessive use of cash bail in the federal courts by making the defendant's appearance at trial, rather than his or her possible "danger to the community" during the pretrial period, the only factor to be considered in setting bail. Defendant's dangerousness could be used as a criterion in deciding bail in the special case of a capital offense charge.

The Bail Reform Act of $1984^{9}$ reversed much of this thinking by providing for the inclusion of information on the defendant's potential dangerousness to the community in deciding the severity of bail decisions. The effect of this legislation was explicitly to give bail decision making the dual function described above, encompassing both a concern for flight risk and protection of the community from the potential dangerousness of the

\footnotetext{
${ }^{7}$ This debate over the legitimate function of bail is refiected in two landmark cases heard by the Supreme Court in 1951. In Stack v. Boyle (72 S. Ct. 1) and Carlson v. Landon (72 S. Ct. 525) the majority opinions laid out contradictory criteria for deciding bail and have subsequently been the source of support for the two opposing views identified. To support the dual assertion that the defendant does not have a constitutional right to bail and that the use of bail for preventive detention is legitimate, Mitchell (1969) and Hess (1971) cite the opinion delivered in Carlson v. Landon. On the other hand, Foote (1954), Harvard Law Review (1966), Fabricant (1969), Tribe (1970), and Borman (1971) rely on the decision in Stack v. Boyle to argue for a right to bail while also insisting that preventive detention is unconstitutional. The cases decided by the Supreme Court since 1951 are extensions of these two views. In Herzog v. U.S. (1955), Reynolds v. U.S. (1959), Brady v. U.S. (1961), Brady v. U.S. (1962), and Fernandez v. U.S. (1961) the Supreme Court argued the role of bail is that of assuring appearance. On the other hand, decisions in Carbo v. U.S. (1962), Sellars v. U.S. (1968), and Russell v. U.S. (1968) maintained that threat to the community is a legitimate criterion in the determination of pretrial release decisions. The court relied on the defendant's prior record and use of a weapon as indicators of dangerousness. We have relied on Goldkamp's (1979) earlier research in presenting the history of the debate as it has been expressed in court decisions relevant for this research. See footnote 12 for most recent decisions.

${ }^{8}$ The Bail Reform Act of 1966 Pub. L. No. 89-465, 80 Stat. 214

'The Bail Reform Act of 1984 Pub. L. No. 94-473, 98 Stat, 1976.
} 
released defendant. This dual function is reinforced by the recent Supreme Court decision in U.S. v. Salerno. ${ }^{10}$ The majority opinion in this case held that preventive detention prior to trial is not unconstitutional, because "Congress formulated the detention provisions not as punishment for dangerous individuals, but as a potential solution to the pressing societal problem of crime committed by persons on release." By this decision the Supreme Court reversed the lower Court of Appeal's decision (3142) that "authorization of pretrial detention on the ground of future dangerousness is facially unconstitutional as a violation of the Fifth Amendment's substantive due process guarantee."

While it is clear that the 1984 act and the recent Supreme Court decision in Salerno mark a shift in the formal legal functions of bail, it is not so clear that lower-court practices were free of this dual function prior to these higher-court and legislative developments. Indeed, it may well be as anthropologist Paul Bohannon (1965) suggested some time ago, that such changes only reinstitutionalize existing practices. That is, law may move from the bottom up, as well as from the top down. As we note further below, examination of court practices after the 1966 act, but before the 1984 act, can provide a test of this possibility. First, however, we review prior research on bail decision making.

\section{PRIOR RESEARCH}

Early studies of pretrial release sought to document a widespread and ill-founded reliance on cash bail and its differential impact on the poor. An apparently discriminatory impact of cash bail on the poor was often demonstrated, and in the process a range of legal and extralegal variables was identified that must be included in any properly specified model of pretrial release decisions. For example, Beeley (1927) found that risk of nonappearance was unrelated to conditions of pretrial release but that access to freedom was largely a function of defendants' financial resources. Foote (1954) and Alexander et al. (1958) similarly found cash bail to be the most frequent condition of release. Although both of these studies found a relationship between charge and bail outcome, Foote's analysis again indicated that the defendant's economic status was related to pretrial detention.

The above findings suggested economic discrimination and led to an interest among policy makers in determining which defendant attributes, if any, were empirically linked to subsequent non-appearance, or "flight risk" (see Ares et al., 1966; Freed and Wald, 1964). The results of these efforts

${ }^{10}$ U.S. v. Salerno 794 F. 2 d. 64 (2d. cir), cert granted, 107 S. Ct. (1986). 
to develop measures of flight risk based on defendant attributes, such as ties to the community, were inconclusive (see Gottfredson, 1981; Feeley and McNaughton, 1974; Clarke et al., 1976; Landes, 1973, 1974; Christenson, 1971). Nonetheless, consideration of "community ties" achieved a legal status in the determination pretrial release decisions through the 1966 Bail Reform Act and subsequent reform legislation. This is reflected in our treatment of community ties in the analysis below.

Another group of studies implicitly or explicitly employs the criteria of the 1966 Bail Reform Act to distinguish between legal and extralegal determinants of pretrial release decisions. The earlier of these studies are primarily descriptive and rely on frequencies and percentage differences. Nonetheless, Bynum (1977) reports that net of offense charged and prior record, defendant's income is associated with nonfinancial release (i.e., release on recognizance, or ROR). Fleming's study of Detroit and Baltimore found relationships between contextual factors, such as the social, political, and organizational characteristics of local government, and the use of cash bail. A comparison across 20 jurisdictions from 1962 to 1971 by Thomas (1976) reveals a decrease in the use of preventive detention and an increase in the use of ROR.

Turning to studies utilizing multivariate techniques, Goldkamp (1979) found that controlling for income-, job-, and asset-related variables, offense seriousness and defendant's prior record had a significant impact on release decisions. However, community ties did not have a significant effect. Nagel (1983) also found charge severity to have a significant effect on release decisions, while extralegal variables, including race and social class, had only minor effects. More specifically, Nagel reported that race had no significant effect on the ROR decision and only a small effect on the bail amount and the decision to offer a cash alternative. Nagel (1983, p. 506) concluded that "in this jurisdiction, for this sample during the period studied, age, race, sex and education predict poorly pretrial release decisions." The finding of negligible extralegal effects and the cautious contextualization of these results are worthy of special note.

Finally, Farnworth and Horan (1980) use a covariance model to test the interaction of race with social background and procedural factors on the amount of bond. Relying on a large $(N=12,454)$ sample of court cases processed in the North Carolina Court system from January 1967 through April 1969, they found that, regardless of race, defendants in the lower occupational levels receive higher bond amounts. However, their analysis also reveals race-specific effects. They found (1980, p. 392) that "older white defendants and whites who are charged with more serious offenses are liable to greater bond charges." Furthermore, the data indicate that white defendants who retain private counsel receive a lower amount of bond than black 
defendants. The race interaction effects reported by Farnworth and Horan (1980) are important, but they must be interpreted with caution. We have noted extensive and lengthy judicial and legislative debates regarding the functions of bail. These debates underline the likelihood that Farnworth and Horan's models of bail decision making are misspecified in two important ways: by failing to include information on the defendant's dangerousness to the community upon release and information on the defendant's likelihood of jumping bail. Failing to include these variables overlooks three decades of debate over the variables legally relevant to the bail decision and fails to address the question of whether the effect of legally relevant variables varies with defendant's race. We return to this study below since their research interests overlap with our own.

The research literature briefly reviewed covers a period of over 30 years, focusing primarily on policy issues (cf. Goldkamp, 1981, 1985, 1987) that followed from the legislative and judicial actions described above. Of perhaps greatest interest is the fact that community ties scales were developed in an attempt to provide an objective method of estimating flight risk and, thereby, to reduce inappropriate judicial reliance on extralegal criteria in determining pretrial release. These efforts failed to produce reliable and valid predictive scales (Goldkamp, 1983, 1985), but the concept of community ties has nonetheless become a legally sanctioned part of the decision-making process. Meanwhile, the research literature indicates that there is a wide latitude of discretion in making pretrial release decisions, with the consequence that there is detainment of defendants in no particular relation to the flight risk they pose. However, the exact role of race and other stratification resources, along with a range of other legal and extralegal variables identified above, including dangerousness, remains unclear.

\section{PRETRIAL RELEASE DECISIONS IN TEN FEDERAL DISTRICT COURTS}

This research extends the analysis of pretrial release decisions by examining the interplay of race, stratification resources, and a number of other legal and extralegal variables. In this sense our research is consistent with the "legal realist" tradition of sociolegal research (see Nagel, 1983; Stryker et al., 1983), a tradition which seeks to draw a distinction between the "law in action" and the "law in the books." Methodologically, this tradition is expressed in research that examines the main effects of legal (the law in the books) and extralegal (the law in action) variables on judicial decisions.

Our research also goes beyond traditional legal realist scholarship by considering a more subtle role that extralegal variables may play in allocating 
judicial decisions. Our guiding hypothesis, derived from a structural principle thought to operate across stratification systems, is that race of defendant does not enter judicial decisions simply as a main effect but, rather, in interaction with stratification resources and other legal and extralegal variables. An implication of this guiding hypothesis is that the effects of stratification resources and other variables are at least partially contingent on the race of defendants. Put another way, it may be that the full effects of extralegal variables such as race and other stratification resources do not appear until one specifies interactions between legal and extralegal variables (Miethe and Moore, 1986). Of course, identification of such interaction effects not only would be important for policy purposes, but also, as we have emphasized, would illustrate a homology across stratification systems that has not previously been observed.

Since Farnworth and Horan (1980) also have explored race and status interactions in bail decision making, it is important that we note theoretical and methodological differences in our approaches, which we believe serve to strengthen the validity of our findings. First, our covariance models include more complete measures of social background: the defendant's educational level and income. More importantly, our estimates are obtained controlling for two variables, dangerousness and flight risk, that we have seen are of theoretical interest to the ongoing debate over the legal function of bail. We include three measures of community ties in addition to a measure of whether the defendant has a record of jumping bail. The importance of these variables is noted in their main effects (see Table II), indicating their importance as control variables in testing for race interaction effects with social background factors. Finally, we should note, of course, that our research includes $\mathbf{1 0}$ federal court settings, while Farnworth and Horan considered only a single state. We move now to a description of our data and the specification of a structural equation model of pretrial release decisions.

\section{THE DATA}

The data ${ }^{11}$ consist of all 5660 male felony defendants processed from 1974 through 1977 in 10 federal district courts which include the following cities: Eastern and Southern New York (Brooklyn and Manhattan), Northern Illinois (Chicago), Eastern Pennsylvania (Philadelphia), Maryland (Baltimore), Northern Texas (Dallas), Western Missouri (Kansas City), Northern Georgia (Atlanta), Central California (Los Angeles), and Eastern Michigan (Detroit). The data were collected with special provisions for

${ }^{11}$ Data were provided by the Administrative Office of U.S. Courts with the assistance of Guy Willetts, Chief of Probation of the U.S. Courts, and by the National Institute of Mental Health. 
quality control and comprehensiveness made possible through a mandate of Title II of the Speedy Trial Act of 1974 to evaluate pretrial service agencies established under this Act. The provisions of the evaluation included that a population of cases was to be collected during this period. Interviews conducted by two of the authors of this paper with administrators of the pretrial service agencies established in each of these cities, as well as with other court personnel, indicated that full cooperation was achieved in the data collection effort.

\section{STRUCTURAL EQUATION MODEL OF PRETRIAL RELEASE DECISIONS}

The structural equation model of pretrial release decisions that we consider in this paper is specified and estimated within the LISREL framework of Jöreskog and Sörbom (Jöreskog, 1973; Jöreskog and Sörbom, 1981a, b). This general model allows the simultaneous specification of a model linking constructs to indicators and a structural equation model stating the causal relationships among these variables. Two constructs introduced above, stratification resources and community ties, are of particular importance to our analysis. Stratification resources is an extralegal variable that forms an essential link to the larger stratification literature. Community ties is a legal variable that is of steadily increasing policy relevance. We have represented these as outcomes of multiple components within the LISREL model. Our model does not contain any latent or unobservable variables; within a single population it merely provides a way to organize and present a recursive model in observed variables. The LISREL specification does provide additional statistical power in our cross-racial comparisons of the pretrial detention decision.

Below we model determinants of pretrial release as a structure involving the defendants' educational level $\left(\xi_{1}\right)$, income $\left(\xi_{2}\right)$, length of residence $\left(\xi_{3}\right)$, marital status $\left(\xi_{4}\right)$, employment status $\left(\xi_{5}\right)$, history of bail jumping $\left(\xi_{6}\right)$, dangerousness to the community $\left(\xi_{7}\right)$, type of crime $\left(\xi_{8}\right)$, prior felony convictions $\left(\xi_{9}\right)$, race $\left(\xi_{10}\right)$, stratification resources $\left(\eta_{1}\right)$, community ties $\left(\eta_{2}\right)$, and statutory seriousness of the crime $\left(\eta_{3}\right)$. More specifically, the restrictiveness of the pretrial release decision, or in other words bail severity $\left(\eta_{4}\right)$, is modeled as an allocation decision involving a set of exogenous variables, two composite constructs, and one additional endogenous variable. Figure 1 depicts our model of pretrial release decisions, based on the following set of equations:

$$
\begin{aligned}
& \eta_{1}=\gamma_{1,1} \xi_{1}+\gamma_{1,2} \xi_{2} \\
& \eta_{2}=\gamma_{2,3} \xi_{3}+\gamma_{2,4} \xi_{4}+\gamma_{2,5} \xi_{5} \\
& \eta_{3}=\gamma_{3,7} \xi_{7}+\gamma_{3,8} \xi_{8}+\gamma_{3,9} \xi_{9}+\zeta_{3}
\end{aligned}
$$




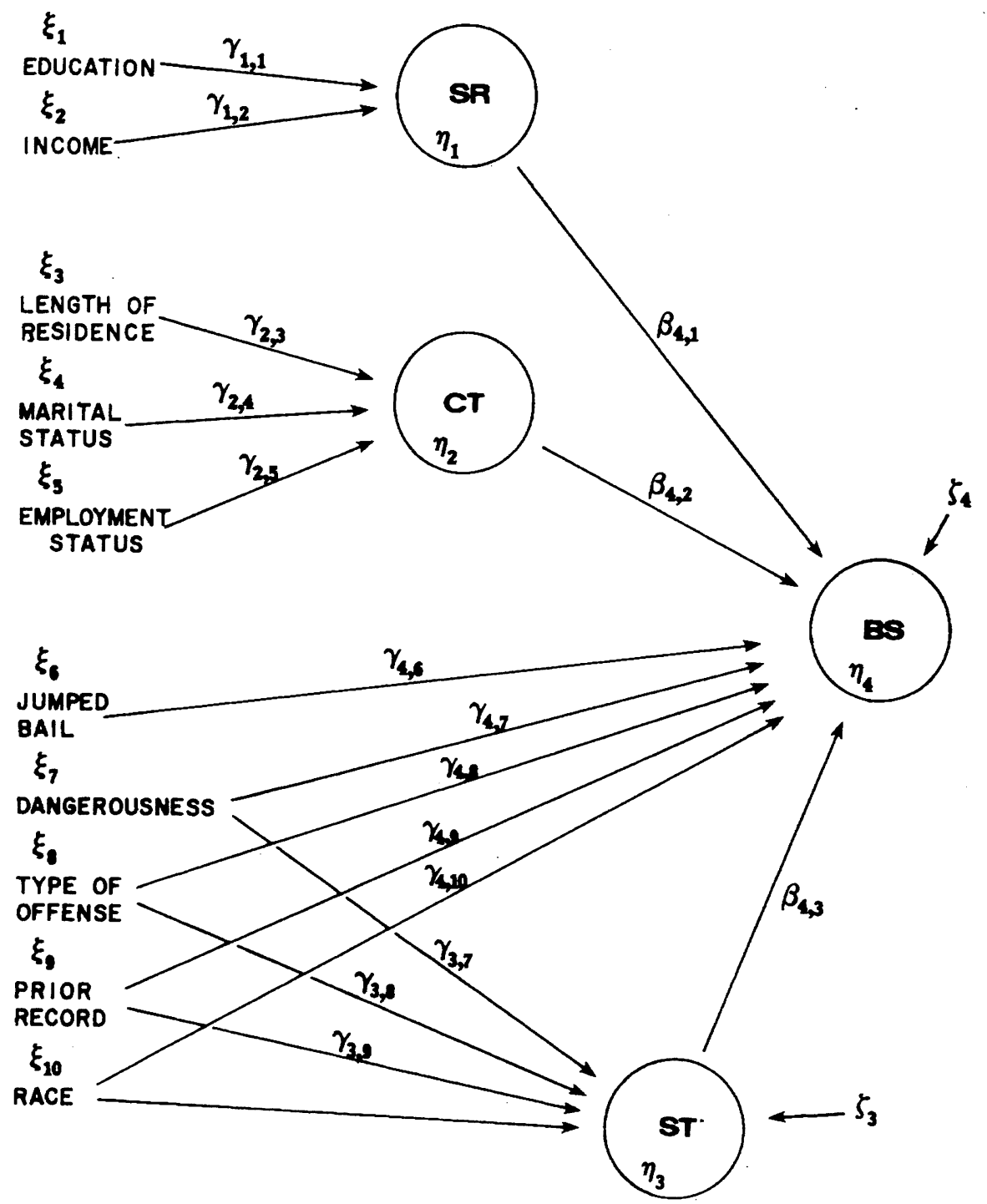

Fig. 1. Path model of the determinants of bail decision making.

$$
\eta_{4}=\beta_{4,1} \eta_{1}+\beta_{4,3} \eta_{3}+\gamma_{4,6} \xi_{6}+\gamma_{4,7} \xi_{7}+\gamma_{4,8} \xi_{8}+\gamma_{4,9} \xi_{9}+\gamma_{4,10} \xi_{10}+\beta_{4,3} \eta_{3}+\zeta_{4}
$$

where

$\xi_{1}=1$ if defendant completed high school or its equivalent, $=0$ if defendant did not complete high school;

$\xi_{2}=$ defendant's yearly income; 
$\xi_{3}=$ defendant's months of residence in the community;

$\xi_{4}=1$ if defendant is married or in common-law relationship, $=0$ if defendant is single, divorced or widowed;

$\xi_{5}=1$ if defendant is employed, $=0$ if defendant is unemployed;

$\xi_{6}=1$ if defendant has previously jumped bail, $=0$ if defendant has not jumped bail;

$\xi_{7}=1$ if defendant ever used a weapon in a crime-dangerous, $=0$ if defendant has not used a weapon-not dangerous;

$\xi_{8}=1$ is defendant is charged with white-collar crime, $=0$ if defendant is charged with conventional crime;

$\xi_{9}=1$ if defendant has a record of adult felony convictions, $=0$ if defendant has no prior adult felonies;

$\xi_{10}=1$ if defendant is black, $=0$ is defendant is white;

$\eta_{3}=$ maximum sentence defendant is exposed to by statute; and

$\eta_{4}=1$ if defendant receives personal recognizance,

$=2$ unsecured bond,

$=3$ unsecured bond plus supervision, $=4$ bail contingent on a $10 \%$ cash deposit, $=5$ bail contingent on a $10 \%$ cash deposit plus supervision, $=6$ bail with collateral or collateral plus supervision, $=7$ bail contingent on a surety bond, or $=8$ bail contingent on a surety bond plus supervision, $=9$ if defendant is denied bail.

Note that the final endogenous variable, bail severity $\left(\eta_{4}\right)$, is an ordinal variable coded from least to most restrictive in terms of the conditions established for pretrial release or its denial. This approximates an interval scale of the severity of this decision.

Some additional detail is necessary about the variables included in our analysis. We have already indicated that stratification resources is a composite that is operationalized as a linear function of education and income. Although the Bail Reform Act of 1966 allowed consideration of financial resources in setting bail conditions, it did so for the purpose of establishing community ties. Community ties is operationalized as a separate construct that is measured as a linear function of length of residence, marital status, and employment. So any effect of stratification resources that is found net of the effect of community ties and other legal variables included in our model can be considered extralegal. Specifying our model with these constructs, we expect that both the composite stratification resources $\left(\eta_{1}\right)$ and community ties $\left(\eta_{2}\right)$ cause bail severity $\left(\eta_{4}\right)$, with the former mediating the extralegal effects of education $\left(\xi_{1}\right)$ and income $\left(\xi_{2}\right)$, and the latter mediating 
the legal effects of length of residence $\left(\xi_{3}\right)$, marital status $\left(\xi_{4}\right)$, and employment status $\left(\xi_{5}\right)$.

In the analysis that follows, $\gamma_{1,1}$ and $\gamma_{2,3}$ are fixed equal to 1.00 for purposes of normalization (see Bielby et al., 1977). When the coefficients leading to stratification resources and community ties, respectively, are determined in models with composite variables such as ours, the two composite variables are known exactly. Furthermore, the variables cause the composite variables as indicated, rather than being caused by the latent construct, as in factor analysis.

The remaining five exogenous variables in the model allow us to examine the net effect of information thought to affect the bail decision. These variables are dichotomies indicating whether the defendant has ever jumped bail $\left(\xi_{6}\right)$, is dangerous in the sense of having used a weapon $\left(\xi_{7}\right)$, has previous adult felony convictions $\left(\xi_{9}\right)$, has committed a white-collar crime $\left(\xi_{8}\right)$, and is black $\left(\xi_{10}\right)$. Only the white-collar crime variable requires further comment. We include this variable because of the uncertainty in the literature (see Hagan et al., 1980; Wheeler et al., 1982; Hagan and Parker, 1985) as to whether these offenses result in lenient treatment and because this variable provides another kind of stratification measure for our analysis. We developed this measure by first listing offenses against the United States Code that might plausibly fall within the category of whitecollar crime. We then asked United States Attorneys and their Assistants in the $\mathbf{1 0}$ districts whether they would designate these offenses as such. On this basis 31 offenses were consensually identified as white-collar, and the remainder were designated as conventional crimes. ${ }^{12}$

\footnotetext{
${ }^{12}$ A short description of these offenses follows: 15 U.S.C. Section 1 (1976) (antitrust violations); 18 U.S.C. Sections 152, 201, 209, 287, 643, 648, 657, 658, 664, 1001, 1005, 1006, 1010, 1012, 1014, 1341, 1343 (bankruptcy - concealment of assets, false oaths and claims, bribery; bribery, graft, and conflicts of interest-bribery of public officials and witnesses; bribery, graft, and conflicts of interest-salary of government officials and employees payable only by U.S.; bribery, graft, and conflicts of interest-offer to procure public office; claims and services in matters affecting the government-false or fraudulent claims; embezzlement and theftaccounting for public money; embezzlement and theft—custodians, generally misusing funds; embezzlement and theft-lending, credit, and insurance institutions; embezzlement and theft-property mortgaged or pledged to farm credit agencies; embezzlement and theft-theft or embezzlement from employee benefit plan; fraud and false statements-statements or entries generally; fraud and false statements-statements or entries generally; fraud and false statements-bank entries, reports, or false transactions; fraud and false statementsfederal crime institutions entries, reports, and transactions; fraud and false statements-WUD and FHA transactions; fraud and false statements-loan and credit applications generally, also renewals and discounts, crop insurance; mail fraud-frauds and swindles, mail fraudfictitious name or address; mail fraud-fraud by wire, radio, or television respectively); 26 U.S.C. Sections 7201, 7203, 7206 (1976) (attempt to evade or defeat tax, failing to file tax return, fraud and false statements, respectively); 29 U.S.C. Section 501 (1976) (fraudulent acceptance of payments-veterans' benefits).
} 
In addition to the two eta variables, stratification resources and community ties, the model includes two additional endogenous variables, statutory seriousness of the offense $\left(\eta_{3}\right)$ and bail severity $\left(\eta_{4}\right)$. Statutory seriousness is measured by the maximum prison sentence provided in the United States Code for the charge initially placed against the offender. This is obviously a legal variable, while any effect of being charged with a whitecollar offense net of statutory seriousness and the other legal variables included in our model is clearly extralegal. As indicated earlier, the final endogenous variable in the model is an approximate interval ordering from least to most severe in the restrictiveness of the pretrial release decision or, in other words, a measure of bail severity.

The path coefficient $\left(\beta_{4,3}\right)$ estimating the effect of statutory seriousness on bail severity is specified because it frequently is assumed that the severity of the potential sanction is an element involved in the defendant's consideration of flight and should, therefore, be a factor considered in the determination of pretrial release conditions. The model specifies main effects of stratification resources and community ties on bail severity. The remaining five exogenous variables, type of charge, record of bail jumping, prior felony convictions, race, and dangerousness, are allowed to affect bail severity directly. Only dangerousness, type of charge, and prior record are allowed also to affect bail severity indirectly through the endogenous variable statutory seriousness of the offense.

We allow type of offense to affect statutory severity $\left(\eta_{3}\right)$ from an interest in determining if being charged with a white-collar offense affects bail severity through statutory seriousness, as a result of the less severe sanctions specified by law for this type of crime. As indicated above, inclusion of this indirect influence of type charge on bail severity assures that the further estimation of the direct effect $\left(\xi_{4,8}\right)$ of being charged with a white-collar offense on bail severity is not contaminated by the differential statutory seriousness of these crimes. The direct effect of type of offense on bail severity is, in this sense, extralegal.

The dangerousness of the defendant, as indicated by use of a weapon in this or earlier crimes, is specified also in the model as a main effect on bail severity $\left(\gamma_{4,7}\right)$. Recall that the Bail Reform Act of 1966 was explicit in indicating that dangerousness of the defendant is an extralegal criterion in determining pretrial release. ${ }^{13}$ As noted earlier, our second concern is

\footnotetext{
${ }^{13}$ Since the Bail Reform Act of 1966 , a number of case decisions have served to clarify further the purpose of bail, each consistent with the act. The following are only a sampling of such cases: U.S. v. Parr, U.S. v. Cramer, U.S. v. Smith, U.S. v. Bronson, Bell v. Wolfish, and U.S. $v$. Edwards, Schall $v$. Martin. In addition, it should be noted that the additional complexity in the flight risk and danger to the community debate provided by the Bail Reform Act of 1984 does not apply to the analysis here since the data are of defendants processed from 1974 to 1977.
} 
whether there is evidence indicating that prior to the Bail Reform Act of 1984 magistrates routinely included information on the defendant's dangerousness in deciding the outcome severity of the bail decision at a time during which such information was legislatively prohibited. Comparison of the coefficients for dangerousness and community ties provides a measure of the relative importance placed on these two types of information in light of the contradictory mandates of the two Bail Reform Acts.

\section{RESULTS}

We turn now to a discussion of the results of our data analysis. This discussion is organized around an examination of the direction and magnitude of each estimated coefficient and an examination of a series of chisquare tests of invariance of selected parameter estimates across racial groups. The latter, of course, reflects our interest in the variable influence of stratification resources and other legal and extralegal variables across these groups. First, however, we consider the full sample of white and black defendants.

Table $\mathrm{I}$ is the correlation matrix used in estimating the LISREL model for the 5660 white and black male felony defendants processed through the

Table I. Correlation Matrix for the Total Sample of Felony Male Defendants in Ten Federal District Courts ${ }^{a}$

\begin{tabular}{|c|c|c|c|c|c|c|c|c|c|c|c|c|}
\hline & $\xi_{1}$ & $\xi_{2}$ & $\xi_{3}$ & $\xi_{4}$ & $\xi_{5}$ & $\xi_{6}$ & $\xi_{7}$ & $\xi_{8}$ & $\xi_{9}$ & $\xi_{10}$ & $\eta_{3}$ & $\eta_{4}$ \\
\hline$\xi_{1}$ & 1.00 & & & & & & & & & & & \\
\hline$\xi_{2}$ & 0.24 & 1.00 & & & & & & & & & & \\
\hline$\xi_{3}$ & 0.01 & 0.12 & 1.00 & & & & & & & & & \\
\hline$\xi_{4}$ & 0.03 & 0.24 & 0.05 & 1.00 & & & & & & & & \\
\hline$\xi_{s}$ & 0.17 & 0.77 & 0.08 & 0.17 & 1.00 & & & & & & & \\
\hline$\xi_{6}$ & -0.10 & -0.11 & -0.09 & -0.03 & -0.10 & 1.00 & & & & & & \\
\hline$\xi_{7}$ & -0.03 & -0.06 & -0.02 & -0.02 & -0.05 & -0.05 & 1.00 & & & & & \\
\hline$\xi_{8}$ & 0.24 & 0.21 & 0.10 & 0.08 & 0.14 & -0.07 & -0.06 & 1.00 & & & & \\
\hline$\xi_{9}$ & -0.11 & -0.13 & -0.07 & -0.05 & -0.11 & 0.17 & 0.11 & -0.10 & 1.00 & & & \\
\hline$\xi_{10}$ & -0.16 & -0.26 & -0.01 & -0.06 & -0.14 & 0.08 & 0.02 & -0.12 & 0.03 & 1.00 & & \\
\hline$\eta_{3}$ & -0.06 & -0.08 & -0.04 & -0.08 & -0.05 & 0.22 & 0.08 & 0.22 & 0.03 & 0.04 & 1.00 & \\
\hline $\begin{array}{l}\eta_{4} \\
\text { Difference }\end{array}$ & -0.10 & -0.11 & -0.15 & -0.07 & -0.10 & -0.16 & 0.17 & -0.16 & 0.18 & 0.03 & 0.14 & 1.00 \\
\hline in means ${ }^{b}$ & -0.16 & -0.23 & -0.01 & -0.06 & -0.14 & 0.08 & 0.02 & -0.12 & 0.03 & - & 0.03 & 0.03 \\
\hline SD & -0.89 & 21.57 & 0.99 & 0.49 & 0.48 & 0.38 & 0.17 & 0.33 & 2.02 & - & 6.75 & 0.29 \\
\hline
\end{tabular}

${ }^{a}$ Variables: $\xi_{1}$ (educational level), $\xi_{2}$ (income level), $\xi_{3}$ (length of residence), $\xi_{4}$ (marital status), $\xi_{5}$ (employment status), $\xi_{6}$ (jumped bail), $\xi_{7}$ (dangerousness), $\xi_{8}$ (white-collar crime), $\xi_{9}$ (prior record), $\xi_{10}$ (race), $\eta_{3}$ (statutory seriousness), and $\eta_{4}$ (severity of bail outcome).

${ }^{b}$ The mean of each variable in the analysis was lost and cannot be generated. By way of providing some information on the variable means we regressed dependent's race on each variable, providing a difference of means across the two groups. This information is recorded for convenience. 
Table II. LISREL Estimates, $z$ Values, and Standardized Coefficients for Parameters in Model 1 Estimated on Pooled Data ${ }^{a}$

\begin{tabular}{|c|c|c|c|c|}
\hline & \multicolumn{4}{|c|}{ Endogenous variable } \\
\hline & $\begin{array}{c}\eta_{1} \\
\text { (stratification } \\
\text { resources) }\end{array}$ & $\begin{array}{c}\eta_{2} \\
\text { (community } \\
\text { ties) }\end{array}$ & $\begin{array}{c}\eta_{3} \\
\text { (statutory } \\
\text { severity) }\end{array}$ & $\begin{array}{c}\eta_{4} \\
\text { (bail } \\
\text { severity) }\end{array}$ \\
\hline \multicolumn{5}{|l|}{ Exogenous variable } \\
\hline$\xi_{1}$ (education) & 1.00 & & & \\
\hline \multirow{4}{*}{$\xi_{2}$ (income) } & 0.97 & & & \\
\hline & 0.08 & & & \\
\hline & 0.11 & & & \\
\hline & $(0.32)$ & & & \\
\hline \multirow[t]{2}{*}{$\xi_{3}$ (length of residence) } & & 1.00 & & \\
\hline & & 0.84 & & \\
\hline \multirow[t]{3}{*}{$\xi_{4}$ (marital status) } & & 0.58 & & \\
\hline & & 0.24 & & \\
\hline & & $(3.17)^{*}$ & & \\
\hline \multirow[t]{3}{*}{$\xi_{5}$ (employment status) } & & 0.92 & & \\
\hline & & 0.38 & & \\
\hline & & $(3.33)^{* *}$ & & \\
\hline \multirow{2}{*}{$\xi_{6}$ (jumped bail) } & & & & 0.58 \\
\hline & & & & 0.06 \\
\hline \multirow{3}{*}{$\xi_{7}$ (dangerousness) } & & & 2.46 & $\begin{array}{l}(4.68)^{* n+} \\
2.12\end{array}$ \\
\hline & & & 0.06 & 0.13 \\
\hline & & & $(4.87)^{* *}$ & $(10.25)^{* *}$ \\
\hline \multirow[t]{3}{*}{$\xi_{8}$ (type of offense) } & & & -4.33 & 0.60 \\
\hline & & & -0.21 & -0.07 \\
\hline & & & $(16.29)^{* *}$ & $(5.16)^{* *}$ \\
\hline \multirow[t]{3}{*}{$\xi_{9}$ (prior record) } & & & -0.01 & 1.62 \\
\hline & & & -0.001 & 0.11 \\
\hline & & & $(0.03)$ & $(8.98)^{* *}$ \\
\hline \multirow[t]{3}{*}{$\xi_{10}$ (race) } & & & 0.06 & -0.08 \\
\hline & & & 0.005 & -0.02 \\
\hline & & & $(0.36)$ & $(1.14)$ \\
\hline \multicolumn{5}{|l|}{ Endogenous variable } \\
\hline \multirow[t]{3}{*}{$\eta_{1}$ (stratification resources) } & & & & -0.19 \\
\hline & & & & -0.06 \\
\hline & & & & $(4.61)^{* *}$ \\
\hline \multirow[t]{3}{*}{$\eta_{2}$ (community ties) } & & & & -0.42 \\
\hline & & & & -0.18 \\
\hline & & & & $(11.74)^{* *}$ \\
\hline \multirow[t]{3}{*}{$\eta_{3}$ (statutory severity) } & & & & 0.04 \\
\hline & & & & 0.09 \\
\hline & & & & $(7.46)^{* *}$ \\
\hline \multicolumn{5}{|l|}{ Overall model $\chi^{2}=32.06$} \\
\hline $\mathrm{df}=6$ & & & & \\
\hline$P=0.000$ & & & & \\
\hline
\end{tabular}

${ }^{a}$ Order of reported findings: LISREL estimates, standardized coefficients, $z$ values.

${ }^{*} P<0.01$.

${ }^{* *} P<0.001$. 
10 federal district courts. Table II presents the estimated path coefficients and their associated levels of statistical significance. We consider the legal effects first. The latent variable community ties has the legally expected effect of reducing bail severity $\left(\beta_{4,2}=-0.42, P<0.001\right)$. This is as allowed by the Bail Reform Act of 1966 . Also, the path indicates that defendants with records of jumping bail are likely to receive more severe bail conditions $\left(\gamma_{4,6}=0.58, P<0.001\right)$, as are also defendants with prior felony records $\left(\gamma_{4,9}=1.62, P<0.001\right)$.

We turn now to extralegal influences on pretrial release decisions. The latent variable stratification resources exerts a considerable and statistically significant direct effect $\left(\beta_{4,1}=-0.19, P<0.001\right)$ on bail severity. As expected, but contrary to the presumed purposes of the bail reform efforts, bail severity increases with declining stratification resources. Race, on the other hand, does not significantly influence $\left(\gamma_{4,10}=-0.08, P>0.05\right)$ pretrial release. We return to this finding below. Again contrary to the expressed intent of the Bail Reform Act, our measure of dangerousness increases bail severity $\left(\gamma_{4,7}=2.12, P<0.001\right)$. These data indicate that dangerousness clearly influenced bail severity before the Bail Reform Act of 1984 and U.S. v. Salerno (1986) legitimized consideration of this factor.

Finally, being charged with a white-collar crime both directly $\left(\gamma_{4,8}=\right.$ $-0.60, P<0.001)$ and indirectly benefits the defendant in terms of reduced bail severity. The indirect effect is through the lower statutory seriousness of white-collar offenses $\left(\gamma_{3,8}=-4.33, P<0.001\right)$. At least the former effect can be considered extralegal, as it occurs independent of the statutory effect.

So far we have seen that extralegal as well as legal variables significantly affect the allocation of pretrial release decisions. These findings constitute an advance in the sense of estimating the effects of stratification resources and community ties as composite constructs in models of pretrial release decisions, and they identify a broader range of extralegal effects on pretrial release decisions than previously has been established. However, these findings do not contradict earlier studies in any explicit way. It is of particular interest that earlier studies have also found negligible main effects of race in bail decision making. However, we move now to the examination of the effects of stratification resources and other legal and extralegal variables across racial groups as a means of testing the structural principle that is central to this paper, namely, that stratification resources and other variables interact with defendant's race in their effect on bail severity. To pursue this analysis, the population of felony defendants is split into whites and blacks and Model 1 is examined within each group, with the model modified only to the extent of excluding race as an exogenous variable.

Tables III and IV present the correlation matrices for the 2785 black and 2875 white male felony defendants, respectively. Table $\mathrm{V}$ indicates the 
Table III. Correlation Matrix for Black Male Felony Defendants in Ten Federal District Courts $^{a}$

\begin{tabular}{lrrrrrrrrrrr}
\hline & $\xi_{1}$ & $\xi_{2}$ & $\xi_{3}$ & $\xi_{4}$ & $\xi_{5}$ & $\xi_{6}$ & $\xi_{7}$ & $\xi_{8}$ & $\xi_{9}$ & $\eta_{3}$ & $\eta_{4}$ \\
\hline$\xi_{1}$ & 1.00 & & & & & & & & & & \\
$\xi_{2}$ & 0.18 & 1.00 & & & & & & & & & \\
$\xi_{3}$ & 0.02 & 0.09 & 1.00 & & & & & & & & \\
$\xi_{4}$ & 0.03 & 0.20 & -0.05 & 1.00 & & & & & & & \\
$\xi_{5}$ & 0.14 & 0.79 & 0.06 & 0.16 & 1.00 & & & & & & \\
$\xi_{6}$ & -0.06 & -0.13 & -0.09 & -0.03 & -0.12 & 1.00 & & & & & \\
$\xi_{7}$ & -0.03 & -0.07 & 0.01 & -0.03 & -0.07 & 0.04 & 1.00 & & & & \\
$\xi_{8}$ & 0.18 & 0.17 & 0.06 & 0.02 & 0.13 & -0.02 & -0.05 & 1.00 & & & \\
$\xi_{9}$ & -0.06 & -0.10 & 0.07 & -0.04 & -0.08 & 0.14 & 0.08 & -0.06 & 1.00 & & \\
$\eta_{3}$ & -0.03 & -0.08 & -0.03 & -0.10 & -0.06 & -0.03 & 0.11 & -0.18 & 0.02 & 1.00 & \\
$\eta_{4}$ & -0.12 & -0.11 & -0.14 & -0.04 & -0.11 & 0.08 & 0.18 & -0.11 & 0.10 & 0.14 & 1.00 \\
\hline
\end{tabular}

${ }^{a}$ Variables: $\xi_{1}$ (educational level), $\xi_{2}$ (income level), $\xi_{3}$ (length of residence), $\xi_{4}$ (marital status), $\xi_{5}$ (employment status), $\xi_{6}$ (jumped bail), $\xi_{7}$ (dangerousness), $\xi_{8}$ (white-collar crime), $\xi_{9}$ (prior record), $\eta_{3}$ (statutory seriousness), and $\eta_{4}$ (severity of bail outcome).

likelihood-ratio chi-square test statistics with their associated degrees of freedom for each cross-group test of invariance and the probability level for each test. It should be noted that with cross-group comparisons it becomes necessary statistically to place equality constraints on indices of constructs. Williams and Thomson (1983) point out that values of structural coefficients are dependent on how one chooses to normalize the constructs.

Table IV. Correlation Matrix for White Male Felony Defendants in Ten Federal District Courts $^{a}$

\begin{tabular}{|c|c|c|c|c|c|c|c|c|c|c|c|}
\hline & $\xi_{1}$ & $\xi_{2}$ & $\xi_{3}$ & $\xi_{4}$ & $\xi_{5}$ & $\xi_{6}$ & $\xi_{7}$ & $\xi_{8}$ & $\xi_{9}$ & $\eta_{3}$ & $\eta_{4}$ \\
\hline$\xi_{1}$ & 1.00 & & & & & & & & & & \\
\hline$\xi_{2}$ & -0.23 & 1.00 & & & & & & & & & \\
\hline$\xi_{3}$ & -0.05 & 0.08 & 1.00 & & & & & & & & \\
\hline$\xi_{4}$ & 0.02 & 0.27 & 0.13 & 1.00 & & & & & & & \\
\hline$\xi_{5}$ & 0.14 & 0.76 & 0.09 & 0.18 & 1.00 & & & & & & \\
\hline$\xi_{6}$ & -0.11 & -0.12 & -0.12 & -0.03 & -0.09 & 1.00 & & & & & \\
\hline$\xi_{7}$ & -0.04 & -0.07 & -0.05 & -0.02 & -0.05 & 0.08 & 1.00 & & & & \\
\hline$\xi_{8}$ & 0.26 & 0.26 & 0.13 & 0.15 & 0.16 & -0.09 & -0.06 & 1.00 & & & \\
\hline$\xi_{9}$ & -0.16 & -0.17 & -0.11 & -0.05 & -0.15 & 0.23 & 0.15 & -0.14 & 1.00 & & \\
\hline$\eta_{3}$ & -0.08 & -0.09 & -0.04 & -0.07 & -0.05 & -0.01 & 0.04 & -0.25 & 0.04 & 1.00 & \\
\hline$\eta_{4}$ & -0.11 & -0.17 & -0.21 & -0.13 & -0.15 & -0.16 & 0.14 & -0.19 & 0.26 & 0.14 & 1.00 \\
\hline
\end{tabular}

${ }^{a}$ Variables: $\xi_{1}$ (educational level), $\xi_{2}$ (income level), $\xi_{3}$ (length of residence), $\xi_{4}$ (marital status), $\xi_{5}$ (employment status), $\xi_{6}$ (jumped bail), $\xi_{7}$ (dangerousness), $\xi_{8}$ (white-collar crime), $\xi_{9}$ (prior record), $\eta_{3}$ (statutory seriousness), and $\eta_{4}$ (severity of bail outcome). 
Table V. Chi-Square, Degrees of Freedom, and Probability Level for Models of Invariance Across Race Groups for Male Defendants

\begin{tabular}{lllll}
\hline \multicolumn{1}{c}{ Model $^{a}$} & $\chi^{2}$ & df & $P$ \\
\hline 1: $\quad$ Pooled model constraining the & & & \\
$\quad$ indices of SR and CT to be equal & 53.65 & 15 & 0.00 \\
2: $\quad$ Invariance of $\beta_{4,1}$ cross groups & 59.12 & 16 & 0.00 \\
3: Invariance of $\beta_{4,2}$ cross groups & 55.10 & 16 & 0.00 \\
4: Invariance of $\gamma_{4,6}$ cross groups & 56.23 & 16 & 0.00 \\
5: Invariance of $\gamma_{4,7}$ cross groups & 57.42 & 16 & 0.00 \\
6: Invariance of $\gamma_{4,8}$ cross groups & 56.59 & 16 & 0.00 \\
7: Invariance of $\gamma_{4,9}$ cross groups & 70.50 & 16 & 0.00 \\
8: Invariance of $\gamma_{3,7}$ cross groups & 61.53 & 16 & 0.00 \\
9: Invariance of $\gamma_{3,8}$ cross groups & 54.18 & 16 & 0.00 \\
10: Invariance of $\gamma_{3,9}$ cross groups & 53.68 & 16 & 0.00 \\
11: Invariance of $\beta_{4,3}$ cross groups & 81.25 & 16 & 0.00 \\
12: Pooled model with no equality constraints & & & \\
& on indices of SR and CT & 43.78 & 12 & 0.00 \\
\hline
\end{tabular}

${ }^{a}$ Models 1 through Model 11 estimated with equality constraints on the indices of CT and SR. (See footnote 8 for discussion.)

Without corrections, our tests of the invariance of structural parameter estimates would be invalid. To avoid this, we follow the strategy of placing equality constraints across groups on our indices of stratification resources and community ties, respectively. ${ }^{14}$

The first test of invariance we consider involves the latent variable that is most central to this analysis, stratification resources. In Table V we see

\footnotetext{
${ }^{14}$ With our interest in group comparisons of structural parameter estimates, it becomes necessary to test the assumption of no differences in the indicators of stratification resources and community ties (Bielby et al., 1977; Gottfredson, 1981; Williams and Thomson, 1983). Using LISREL, we examine whether a model placing equality constraints on the two indicators of stratification resources and the three indicators of community ties provides a better fit to the data than a model that allows these indices to take their respective group values. The null hypothesis tested is Model $1=$ Model 12, where Model 1 is the model of equality constraints across groups for the parameter estimates above and Model 12 is the model of no equality constraints for the above parameter estimates. Table VI provides the results of this test. Model 1 produces a goodness-of-fit statistic of 53.65 with 15 degrees of freedom $(P=0.000)$. Model 12 produces a goodness-of-fit statistic of 43.78 with 12 degrees of freedom $(P=0.000)$. Using the test of the difference between two nested models yields a $\chi^{2}$ of 9.87 with 3 degrees of freedom $(0.05>P>0.02)$. Given the importance of this test for later analysis, we require the chi-square difference test to be statistically significant at $P \leq 0.01$. With this probability level as our criterion we are unable to reject the hypothesis of no differences between the models. We employ Model 1 as the model for our cross-group comparisons. This permits us to test for cross-group differences in the effect of each construct with 1 degree of freedom, rather than with 2 degrees of freedom for stratification resources and 3 degrees of freedom for community ties.
} 
that Model 2, which specifies the effect of stratification resources $\left(\boldsymbol{\beta}_{4,1}\right)$ as invariant across groups, produces a $\chi^{2}=59.12$ with 16 degrees of freedom $(P=0.000)$. Comparing this chi-square value with that obtained for Model 1 , which specifies no equality constraints for stratification resources across groups, produces a chi-square test value in Table VI for the difference between M2 and M1 of 5.46 with 1 degree of freedom. This result allows a rejection of the null hypothesis that $\mathrm{M} 1=\mathrm{M} 2$ at the 0.02 level. The effect of stratification resources on bail severity does vary across racial groups. The parameter estimates presented in Table VII reveal that this difference in effects is in the direction of stratification resources producing a greater reduction in the severity of bail conditions for whites $\left(\beta_{4,1}=-0.33\right)$ than blacks $\left(\beta_{4,1}=-0.12\right)$. That is, although both groups benefit from access to stratification resources, whites benefit more than blacks. This finding supports the assertion that the stratification of defendants in the criminal justice system is similar to that in other institutions of allocation.

We next consider how additional legal and extralegal variables operate across the racial groupings, beginning with the other construct included in our model, community ties. Table $\mathrm{V}$ indicates that Model 3, which specifies the effect of community ties to be invariant across groups, produces a $\chi^{2}=55.10$ with 16 degrees of freedom $(P=0.000)$. The chi-square difference indicated in Table VI between Model 1 and Model 3 is 1.44 with 1 degree of freedom, which does not allow a rejection of the null hypothesis that Model $3=$ Model 1 . The legal variable community ties apparently operates similarly for whites and blacks.

Performing the same chi-square difference test for Model 1 and Model 5 indicates that the effect of the defendant's dangerousness does not vary across groups. Comparisons of Model 4 and Model 6 with Model 1 similarly

Table VI. Chi-Square Difference Tests of Invariance of Specific Estimates Cross Black Male and White Male Defendants

\begin{tabular}{|c|c|c|c|c|c|}
\hline \multicolumn{2}{|r|}{ Model tested } & $\chi^{2}$ difference & df & $P$ & Conclusion \\
\hline $\mathrm{H}_{0}$ : & $\mathrm{M} 1=\mathrm{M} 2$ & 5.46 & 1 & 0.02 & Reject $\mathrm{H}_{0}$ \\
\hline $\mathrm{H}_{0}$ : & $\mathbf{M} 1=\mathbf{M} 3$ & 1.44 & 1 & 0.20 & Fail to reject \\
\hline $\mathrm{H}_{0}$ : & $M 1=M 4$ & 2.57 & 1 & $0.10<P<0.20$ & Fail to reject \\
\hline $\mathbf{H}_{\mathbf{0}}$ : & $\mathrm{M} 1=\mathrm{M} 5$ & 3.76 & 1 & $0.05<P<0.10$ & Fail to reject \\
\hline $\mathbf{H}_{\mathbf{0}}$ : & $\mathrm{M} 1=\mathrm{M} 6$ & 2.93 & 1 & $0.05<P<0.10$ & Fail to reject \\
\hline $\mathrm{H}_{0}$ : & $\mathbf{M} 1=\mathbf{M} 7$ & 16.85 & 1 & $<0.001$ & Reject $\mathrm{H}_{0}$ \\
\hline $\mathrm{H}_{0}$ : & $\mathrm{M} 1=\mathrm{M} 8$ & 7.87 & 1 & $0.001<P<0.01$ & Reject $\mathrm{H}_{0}$ \\
\hline $\mathbf{H}_{0}$ : & $\mathrm{M} 1=\mathrm{M} 9$ & 0.52 & 1 & $>0.70$ & Fail to reject \\
\hline $\mathrm{H}_{0}$ : & $\mathrm{M} 1=\mathrm{M} 10$ & 0.02 & 1 & $>0.80$ & Fail to reject \\
\hline $\mathrm{H}_{0}$ : & $\mathrm{M} 1=\mathrm{M} 11$ & 27.59 & 1 & $<0.0001$ & Reject $\mathbf{H}_{0}$ \\
\hline
\end{tabular}


Table VII. LISREL Estimates, Standardized Coefficients, and $z$ Values for Parameters in Model 1 Estimated Separately for Black and White Defendants ${ }^{a}$

\begin{tabular}{|c|c|c|c|c|c|c|c|c|}
\hline & \multicolumn{4}{|c|}{ Black defendants } & \multicolumn{4}{|c|}{ White defendants } \\
\hline & $\eta_{1}$ & $\eta_{2}$ & $\eta_{3}$ & $\eta_{4}$ & $\eta_{1}$ & $\eta_{2}$ & $\eta_{3}$ & $\eta_{4}$ \\
\hline \multicolumn{9}{|c|}{ Exogenous variables } \\
\hline \multirow[t]{2}{*}{$\xi_{t}$} & 1.00 & & & & 1.00 & & & \\
\hline & 0.96 & & & & 0.96 & & & \\
\hline \multirow{3}{*}{$\xi_{2}$} & 1.21 & & & & 1.21 & & & \\
\hline & 0.15 & & & & 0.15 & & & \\
\hline & $(0.54)$ & & & & $(0.54)$ & & & \\
\hline \multirow{2}{*}{$\xi_{3}$} & & 1.00 & & & & 1.00 & & \\
\hline & & 0.93 & & & & 0.93 & & \\
\hline \multirow[t]{3}{*}{$\xi_{4}$} & & 0.35 & & & & 0.35 & & \\
\hline & & 0.16 & & & & 0.16 & & \\
\hline & & $(2.97)^{* *}$ & & & & $(2.97)^{* *}$ & & \\
\hline \multirow{2}{*}{$\xi_{s}$} & & 0.57 & & & & 0.57 & & \\
\hline & & $\begin{array}{l}0.16 \\
(3.17)^{* *}\end{array}$ & & & & $\begin{array}{c}0.26 \\
(3.17)^{* *}\end{array}$ & & \\
\hline \multirow{3}{*}{$\xi_{6}$} & & & & 0.86 & & & & 0.45 \\
\hline & & & & 0.09 & & & & 0.05 \\
\hline & & & & $(4.40)^{* * *}$ & . & & & $(2.84)^{* *}$ \\
\hline \multirow[t]{3}{*}{$\xi_{7}$} & & & 1.06 & 1.59 & & & 3.98 & 2.41 \\
\hline & & & 0.03 & 0.10 & & & 0.10 & 0.14 \\
\hline & & & $(1.38)$ & $(5.27)^{* * *}$ & & & $(5.61)^{* * *}$ & $(8.35)^{* * *}$ \\
\hline \multirow{3}{*}{$\xi_{8}$} & & & -4.50 & -0.74 & & & -4.10 & -0.34 \\
\hline & & & -0.22 & -0.08 & & & -0.20 & -0.04 \\
\hline & & & $(13.46)^{* * *}$ & $(5.27)^{* * *}$ & & & $(9.17)^{* * *}$ & $(1.79)$ \\
\hline \multirow[t]{3}{*}{$\xi_{9}$} & & & -0.09 & 2.58 & & & -0.003 & 1.10 \\
\hline & & & -0.003 & 0.18 & & & -0.001 & 0.08 \\
\hline & & & $(0.13)$ & $(9.51)^{* * *}$ & & & $(0.004)$ & $(4.67)^{* * *}$ \\
\hline \multicolumn{9}{|c|}{ Engodenous variables } \\
\hline \multirow[t]{3}{*}{$\eta_{1}$} & & & & -0.12 & & & & -0.33 \\
\hline & & & & 0.04 & & & & -0.10 \\
\hline & & & & $(2.25)^{*}$ & & & & $(4.89)^{* * *}$ \\
\hline \multirow[t]{3}{*}{$\eta_{2}$} & & & & -0.58 & & & & -0.66 \\
\hline & & & & -0.22 & & & & -0.25 \\
\hline & & & & $(12.66)^{* * *}$ & & & & $(12.38)^{* * *}$ \\
\hline \multirow{3}{*}{$\eta_{3}$} & & & & 0.04 & & & & 0.05 \\
\hline & & & & 0.10 & & & & 0.11 \\
\hline & & & & $(5.43)^{* * *}$ & & & & $(5.92)^{* * *}$ \\
\hline \multicolumn{9}{|c|}{$\begin{array}{l}\text { Error } \\
\text { distes }\end{array}$} \\
\hline
\end{tabular}

${ }^{a}$ Order of reported findings: LISREL estimates, standardized coefficients, $z$ values.

${ }^{*} P<0.05$.

${ }^{* *} P<0.01$.

${ }^{* * *} P<0.001$. 
indicate that the effects of the defendant's record of bail jumping and type of charge are invariant across groups. Dangerousness, jumping bail, and being charged with a conventional crime all have negative effects that are commensurate for white and black defendants in terms of increasing bail severity.

We turn now to the effects of having a record of prior adult felony convictions. Model 7 constrains the effect of such a record to be invariant across groups and produces a $\chi^{2}=70.50$ with 16 degrees of freedom $(P=$ 0.000 ). Referring to Table VII we see that the obtained $\chi^{2}$ of 16.85 for the difference in Models 1 and 7 with 1 degree of freedom allows rejection of the null hypothesis that $\mathrm{M} 7=\mathrm{M} 1$ at the $P<0.001$ level of significance. Rejection of the null hypothesis indicates that a prior record of adult felony conviction operates differently for whites and blacks. Table VII indicates the source that prior felony conviction produces a greater severity of bail outcome for black $\left(\gamma_{4,9}=2.58\right)$ than white defendants $\left(\gamma_{4,9}=1.10\right)$. Both groups pay for these convictions, but blacks pay more.

Finally, we consider the tests for the cross-group comparisons of coefficients affecting statutory seriousness of the offense $\left(\eta_{3}\right)$ and the effects of statutory seriousness on bail severity. The first two tests, involving the null hypotheses that $\mathrm{M} 1=\mathrm{M} 9$ and $\mathrm{M1}=\mathrm{M} 10$, yield nonsignificant results. This indicates that the effects of type of charge and prior record of felony convictions on statutory seriousness of the offense do not vary across racial groups. However, the statistically significant chi-square difference statistic for the comparison of Model 8 with Model 1 indicates that the effect of dangerousness on statutory severity $\left(\gamma_{3,7}\right)$ does vary across race groups. Referring to Table VII, we see that dangerousness produces an effect of $\gamma_{3,7}=1.06(P<0.001)$ for black defendants, but for white defendants the effect is much stronger, $\gamma_{3,7}=3.98(P<0.001)$. Clearly, dangerousness of the defendant results in a higher statutory severity for white defendants than for black defendants, contrary to expectations derived from labeling or conflict theory.

Referring to Table VII, the effect of statutory seriousness on bail severity also varies across groups. Table VI indicates that Model 11, which specifies an invariance in the effects of statutory seriousness across groups, is significantly different from Model 1 , which allows this effect to vary. The null hypothesis of no difference is rejected. Finally, in Table VII we see that the difference observed is in the form of the statutory seriousness of the offense charged having a greater influence on the bail severity for white than for black defendants. This finding is consistent with Farnworth and Horan's (1980) research challenging further the conflict and labeling theory's onedimensional characterization of disadvantage in the American criminal justice system. 


\section{DISCUSSION AND CONCLUSION}

In this paper we have addressed two concerns. First, we have sought to examine criminal justice decision making at the federal court level as an allocation process based on structural principles that are similar to those of other stratification systems. The present study of pretrial release decisions provides considerable evidence of such an allocation process. To begin, pretrial release decisions in the federal courts are influenced by both legal and extralegal variables. That is, both are a part of the stratification process. On the one hand, variables measuring weak community ties, bail jumping, and prior felony convictions have the effects legally expected under the Bail Reform Act, increasing the severity of pretrial release decisions. These findings hold for estimates obtained on the joint population of defendants (see Table II) and for estimates obtained on race specific populations (see Table VII). On the other hand, variables measuring stratification resources, dangerousness, and being charged with a white-collar crime have effects, unintended by the Bail Reform Act, in effect at the time the cases were processed.

A primary concern in this paper has been to open a new avenue of research on criminal justice decision making by exploring a more subtle structural principle that influences the allocation of pretrial release decisions as well as other stratification processes. This principle is that stratification resources, measured as a multidimensional construct with education and income as its observed components, operate to the greater advantage of whites than blacks. While this and previous studies have found that the main effect of race on pretrial release decisions is negligible, with the exception of Farnworth and Horan's (1980) research, interactions of race with stratification resources have not been explored. As noted earlier, Farnworth and Horan's study of race-specific effects on bail decision making failed to estimate the effect of the defendant's dangerousness to the community and the defendant's record of jumping bail-two variables central to the decades-old debate over defining the legally relevant information to the pretrial release decision. Our findings point to the direct and indirect influence these variables exert on judicial discretion.

This research further indicates that the above structural principle and the interactions it implies do indeed operate in the allocation of pretrial release decisions. That is, stratification resources and prior record of felony convictions act to the disadvantage of black defendants. Most significantly, we find that, although stratification resources reduce the severity of bail decisions for both racial groups, this influence is greater for white than for black defendants. In other words, whites receive the greater advantages that stratification resources provide. These findings support the white public's 
perceptions of inequality in the criminal justice system (Yankerovich, Skelly, and White, Inc., 1977). We say more about black respondents' perceptions below.

However, our findings suggest, contrary to conflict theory and labeling theory, that black defendants are not always placed in a disadvantageous position relative to whites. Our research indicates that increases in the statutory severity of the offense produce more severe outcomes for white defendants than their black counterparts. Moreover, the greater effect of dangerousness on statutory severity for white defendants further contributes to the disadvantage produced by the effect of statutory severity on bail outcome. These findings point to the importance of including information on the defendant's dangerousness in any analysis of race-specific effects on the pretrial release decision.

Our second concern has been to research further the relationship between law and legal practices. Analyzing federal magistrate decision making occurring prior to the Bail Reform Act of 1984, we found that information on the defendant's dangerousness was routinely used to increase the severity of bail decisions. Inclusion of this information was in conflict with the Bail Reform Act of 1966 then in effect. Based on these findings we suggest that; consistent with Bohannon's (1965) assertion concerning a role of law, the Bail Reform Act of 1984 served to reinstitutionalize magistrate norms regarding the operational definition of justice at the bail stage of case processing. These findings are generalizable to federal case processing. Whether these findings apply to state court decision making remains to be investigated.

Returning to our initial interest, the finding that stratification resources work to the greater advantage of whites than blacks helps to make sense of prior research on public perceptions of the criminal justice system. Hagan and Albonetti (1982) report from an analysis of a national sample of Americans that blacks, and especially blacks who have achieved a position in the professional managerial class, perceive that the criminal justice system works to their relative disadvantage. Yet criminal justice research repeatedly casts doubt on such perceptions, finding negligible main effects of race on outcomes (e.g., Kleck, 1981). Our findings suggest an explanation of this paradox. It may be that the influence of race is more complicated than previously recognized, operating in interaction with stratification resources and other legal and extralegal variables. Our findings in particular point to a clear reason why blacks in the professional managerial class perceive so much criminal injustice: in our data, stratification resources simply do not bring the same return in the allocation of pretrial release decisions for blacks as for whites. The lesson seems to be this: as in other stratification 
systems, white defendants in the criminal justice system receive better returns on their resources.

\section{CASES CITED}

Stack v. Boyle 72 S. Ct. 1 (1951)

Carlson v. Landon 72 S. Ct. 525 (1951)

Herzog v. U.S. 75 S. Ct. 348, 349 (1955)

Reynolds v. U.S. 80 S. Ct. 30 (1959)

Brady v. U.S. 81 S. Ct. 197 (1961)

Brady v. U.S. S. Ct. 11 (1962)

Fernandez v. U.S. 81 S. Ct. 642 (1961)

Carbo v. U.S. 82 S. Ct. 662 (1962)

Leigh v. U.S. 82 S. Ct. 994 (1962)

Sellars v. U.S. 89 S. Ct. 36 (1968)

Russell v. U.S. 402 F.2d 185 (D.C. Cir., 1968)

U.S. v. Parr, C.A. Tex, 594 F.2d 440 (1979)

U.S. v. Cramer, C.A. Tex, 451 F. 2d 1198 (1971)

U.S. v. Smith, C.A. 8, 444 F. 2d 61, certinorari denied 92 S. Ct. 1205, 405 U.S. 977, 31L. Ed. 2d 253 (1971)

U.S. v. Bronson 432 F. 2d 537, 139 U.S. App D.C. 379 (1970)

U.S. v. Salerno 794 f.2d. 64 (2d. Cir). cert. granted 107 S. Ct. (1986)

Bell v. Wolfish 441 U.S. 520, 535-538 (1979)

Schall v. Martin 104 S. Ct. 2403, 2417 (1984)

\section{REFERENCES}

Alexander, G. M., Glass, P., Roberts, J., and Schurz, A. (1958). A study of the administration of bail in New York City. Univ. Pa. Law Rev. 106: 685-690.

Ares, C., Rankin, A., and Sturz, H. (1966). The Manhattan Bail Project: An interim report on the use of pretrial parole. N.Y.U. Law Rev. 38: 67-77.

Balbus, I. (1977). Commodity form and legal form: An essay on the "relative autonomy" of the law. Law Soc. Rev. 11: 571-588.

Beeley, A. (1927). The Bail System in Chicago, University of Chicago Press, Chicago (reprinted 1966).

Bielby, W. T., Hauser, R. M., and Featherman, D. L. (1977). Response error of black and nonblack males in models of the intergenerational transmission of socioeconomic status. Am. J. Sociol 82: 1242-1287.

Blumstein, A., Cohen, J., Martin, S., and Tonry, M. (1983). Research on Sentencing: The Search for Reform, National Academy Press, Washington, D.C.

Bohannon, P. (1965). The differing realms of the law. In Nader, L. (ed.), Ethnography of Law, Special Publication, pp. 33-42.

Borman, P. (1971). The selling of preventive detention. Northwest. Law Rev. 65/66: 879-890. 
Bynum, T. (1977). An Empirical Exploration of the Factors Influencing Release on Recognizance, Ph.D dissertation, Florida State University, Tallahassee.

Clarke, S. H., Freeman, J. L., and Koch, G. C. (1976). Bail risk: A multivariate analysis. J. Legal Stud. 5: 341-385.

Duncan, O. D. (1969). Inheritance of poverty or inheritance of wealth? In Moynihan, D. P. (ed.), Understanding Poverty, Basic, New York.

Fabricant, M. (1969). Bail as a preferred freedom and the failures of New York's revision. Buffalo Law Rev. 18: 303-317.

Farnworth, M., and Horan, P. (1980). Separate justice: An analysis of race differences in court processes. Soc. Sci. 9: 381-399.

Featherman, D. L., and Hauser, R. M. (1978). Opportunity and Change, Academic Press, New York.

Feeley, M., and McNaughton, J. (1974). The Pre-Trial Process in the Sixth Circuit: A Quantitative and Legal Analysis, New Haven Pre-Trial Services, New Haven, Conn.

Foote, C. (1954). Compelling appearance in court: Administration of bail in Philadelphia. Univ. Pa. Law Rev. 102:1031-1079.

Foote, C. (1959). The bail system and equal justice. Fed. Probat. 23: 43-54.

Freed, D., and Wald, P. (1964). Bail in the United States: 1964. National Conference on Bail and Criminal, Washington, D.C.

Goldkamp, J. S. (1977). Bail Decisionmaking and the Role of Pretrial Decisionmaking in American Justice, Ph.D. dissertation, School of Criminal Justice, State University of New York at Albany, Albany.

Goldkamp, J. S. (1979). Two Classes of Accused: A Study of Bail and Detention in American Justice, Ballinger, Cambridge, Mass.

Goldkamp, J. S. (1983). Questioning the practice of pretrial detention: Some empirical evidence from Philadelphia. J. Crim. Law Criminol. 74:1556-1588.

Goldkamp, J. S. (1985). Danger and detention: A second generation of bail reform. J. Crim. Law Criminol. 76: 1-74.

Goldkamp, J. S. (1987). Prediction in criminal justice policy development. In Gottfredson, D. M., and Tonry, M. (eds.), Classification and Prediction in Criminal Justice Decision. 9 Crime and Justice, University of Chicago Press, Chicago.

Goldkamp, J. S., Gottfredson, M. R., and Mitchel-Herzfeld, S. (1981). Bail Decision Making: A Study of Policy Guidelines, National Institute of Corrections, Washington, D.C.

Goldkamp, J. S., and Gottfredson, M. R. (1985). Policy Guidelines for Bail: An Experiment in Court Reform, Temple University Press, Philadelphia.

Gottfredson, D. C. (1981). Black-white differences in the educational attainment process: What have we learned? Am. Sociol Rev. 46: 542-557.

Hagan, J., and Albonetti, C. (1982). Race, class and the perception of criminal injustice in America. Am. J. Sociol. 88: 329-355.

Hagan, J. and Bumiller, K. (1983). A review and critique of sentencing research. In Blumstein, A., Cohen, J., Martin, S., and Tontry, M. (eds.), Research on Sentencing: The Search for Reform, National Academy Press, Washington, D.C.

Hagan, J., and Parker, P. (1985). White collar crime and punishment: The class structure and legal sanctioning of securities violations. Am. Sociol. Rev. 50: 302-316.

Hagan, J., Nagel, I., and Albonetti, C. A., (1980). The differential sentencing of white collar offenders in ten federal district courts. Am. Sociol. Rev. 45: 802-820.

Hess, F. (1971). Pre-trial detention and the 1970 D.C. Crime Act-The next step in bail reform. Brooklyn Law Rev. 37: 277-322.

Hout, M. (1984). Occupational mobility of black men: 1962 to 1973. Am. Sociol. Rev. 49: 308-322. 
Humphries, D. and Greenberg, D. (1984). Social control and social formation: A Marxian analysis. In Black, D. (ed.), Toward a General Theory of Social Control, Vol. II. Selected Problems, Academic Press, New York.

Jöreskog, K. (1973). A general method for estimating a linear structural equation system. In Goldberger, A., and Duncan, O. (eds.), Structural Equation Models in the Social Sciences, Seminar Press, New York.

Jöreskog, K., and Sörbom, D. (1981a) LISREL-Analysis of Linear Structural Relationships by the Method of Maximum Likelihood. User's Guide, Version V, National Educational Resources, Chicago.

Jöreskog, K, and Sörbom, D. (1982b). The use of LISREL in sociological model building. In Jackson, D. J., and Borgatta, E. F. (eds.), Factor Analysis and Measurement in Sociological Research, Sage, Beverly Hills, Calif.

Landes, W. (1973). The bail system: An economic approach. J. Legal Stud. 2: 79-91.

Landes, W. (1974). Legality and reality: Some evidence on criminal proceeding. J. Legal Stud. 3: $105-123$.

Lizotte, A. (1978). Extra-legal factors in Chicago's criminal courts: Testing the conflict model of criminal justice. Soc. Problems 25: 564-580.

Kleck, G. (1981). Racial discrimination in criminal sentencing: A critical examination of the evidence with additional evidence on the death penalty. Am. Sociol. Rev. 46: 783-805.

Miethe, T. D., and Moore, C. A. (1986). Racial differences in criminal processing: The consequences of model selection on conclusions about differential treatment. Sociol. $Q$. 27: $217-237$.

Mitchell, J. (1969). Bail reform and the constitutionality of pre-trial detention. Va. Law Rev. 55: 1223-1242.

Morse, W., and Beattie, R. (1932). Survey of the Administration of Criminal Justice in Oregon, University of Oregon, Eugene.

Nagel, I. (1983). The legal/extra-legal controversy: Judicial decisions on pretrial release. Law Soc. Rev. 17: 481-515.

Rossi, P., Waite, E., Bose, C., and Berk, R. (1974). The seriousness of crime: Normative structure and individual differences. Am. Sociol. Rev. 39: 224-237.

Siegel, P. (1965). On the costs of being a negro. Sociol. Inquiry 35: 41-57.

Stryker, R., Nagel, I. H., and Hagan, J. (1983). Methodological issues in court research. Sociol. Methods Res. 11: 469-500.

Thomas, W. H. (1976). The Bail Reform in America, University of California Press, Berkeley.

Tribe, L. (1970). An ounce of detention: Preventive justice in the works of John Mitchell. Va. Law Rev. 56: 371-389.

Weiss, R. (1970). The effect of education on the earnings of blacks and whites. Rev. Econ. Stat. 52: 150-159.

Wheeler, S., Weisbord, D., and Bode, N. (1982). Sentencing the white collar offender: Rhetoric and reality. Am. Sociol. Rev. 47: 641-659.

Wice, P. (1974). Freedom for Sale, Lexington Books, Lexington, Ky.

Williams, R., and Thomson, E. (1983). Notes on the estimation of models with wife-husband data. Center of Demography and Ecology Working Paper 82-58, University of WisconsinMadison.

Wilson, W. J. (1978). The Declining Significance of Race, University of Chicago, Chicago.

Wright, E. O. (1978). Race, class and income inequality, Am. J. Sociol. 83: 1368-1397.

Yankerovich, Skelly, and White, Inc. (1977). The public image of the courts: A national survey of the general public, judges, lawyers, and community leaders. Unpublished report, National Criminal Justice Reference Service, Rockville, Maryland. 